\title{
EDUCAÇÃO AMBIENTAL NA EDUCAÇÃO INFANTIL: COMO E PORQUE SUA ABORDAGEM COM CRIANÇAS NESSA FAIXA ESCOLAR
}

\author{
Denise Alvino Alves; Eclair Maria Da Silva Simeão, Marcos Lupércio Ramos \\ Universidade do Oeste Paulista - UNOESTE, Curso de Pedagogia, Presidente Prudente, SP. E-mail: \\ lupercioramos@yahoo.com.br.
}

\begin{abstract}
RESUMO
Esta pesquisa teve por objetivo analisar, entender e identificar metodologias de como trabalhar educação ambiental na educação infantil, com o intuito de promover o conhecimento sobre as questões ambientais e mecanismos que impliquem em comportamentos mais condizentes com a sustentabilidade ambiental. Visa também, fornecer subsídios aos profissionais da educação que tenham como ambiente de trabalho escolas de educação infantil e como clientela crianças nessa faixa etária. Entende-se ao final, que a educação ambiental deve ser iniciada o quanto mais cedo possível, portanto, ainda no ensino infantil. Para tanto, o profissional da educação e as escolas que trabalham com esse nível da educação formal - o ensino infantil - devem estar preparados para a inserção nos processos de formação escolar da temática ambiental de maneira pragmática, concreta e o mais próximo possível das múltiplas realidades que se apresentam.
\end{abstract}

Palavras-chave: Educação; Ensino Infantil; Educação Ambiental

\section{ENVIRONMENTAL EDUCATION IN EARLY CHILDHOOD EDUCATION: HOW AND WHY YOUR APPROACH WITH CHILDREN THAT SCHOOL BAND}

\begin{abstract}
This research aimed to analyze, understand and identify methodologies for working environmental education in early childhood education, in order to promote knowledge on environmental issues and mechanisms that result in behavior more consistent with environmental sustainability. It also aims to provide subsidies to education professionals who have as desktop preschools and clientele as children in this age group. It is understood the end, that environmental education should be started as soon as possible, therefore, still in kindergarten . Therefore, the professional education and schools that work with this level of formal education early childhood education - should be prepared for inclusion in school education processes of environmental issues in a pragmatic way, concrete and as close to the multiple realities that present themselves.
\end{abstract}

Keywords: Education; Kindergarten; Environmental education. 


\section{INTRODUÇÃO}

A temática que envolve o meio ambiente nos dias atuais é um dos assuntos que aparentemente - tem gerado debates e preocupações maiores entre as autoridades do mundo todo, sendo destaque nas mídias, escolas e congressos. E, dentro dessa temática, segundo autores como Ramos (1999), Oliveira (2000), Dias (2004) e Oliveira (2012), emergiu a educação ambiental (EA) como real possibilidade de formação de cidadãos que exerçam comportamentos que promovam a sustentabilidade ambiental.

Trabalhar educação ambiental na educação infantil cria maiores possibilidades para a formação de cidadãos e cidadãs com maior conscientização e, portanto, melhores comportamentos em relação à temática ambiental e sobre os problemas em relação ao meio ambiente, quer seja ele ainda natural ou somente social.

Envolver a temática ambiental com processos educativos significa promover a educação ambiental, sendo, dessa maneira, importante, pois, de acordo com Oliveira (2000, p. 89) a “[...] educação tem sido sugerida como salvadora dos problemas ambientais [...]", pois pode promover mudanças de comportamentos. Embora o mesmo autor (OLIVEIRA, 2000), ressalte, que sim, a educação formal escolar seja importante no processo das relações homem-meio ambiente, contudo ela não possui os mecanismos básicos que levem ao desenvolvimento sustentável, pois esses seriam inerentes às políticas de governos e de interesse do capital.

Vale lembrar que a educação ambiental na educação infantil tem como principal objetivo iniciar o processo de formação de cidadãos que podem e devem ser conhecedores e responsáveis por seus atos em suas relações em sociedade e na sua interação com o meio ambiente. Porém, não se pode afirmar que apenas o que foi aprendido no ambiente escolar vá fazer a diferença para aprimorar o mundo social e a condição de vida de populações humanas, pois a prática para a mudança deve ser contínua e, em assim sendo, necessariamente abrange outros ambientes como o familiar, por exemplo.

Contudo se pode destacar - e isso é inegável em toda formação do indivíduo - que na escola e na família, é que se dá o ponto de partida ao processo de formação continuada do indivíduo, e cabe a sociedade modificar hábitos a fim de que haja melhorias contínuas com relação à inter-relação com o meio ambiente.

Conforme Oliveira (2000, p. 89):

A educação ambiental deve, sim, ser, encarada como um processo voltado para a apreciação da questão ambiental sob sua perspectiva histórica, antropológica, econômica, social, cultural e ecológica, enfim, como educação política, na medida em que são decisões políticas todas as que, em que qualquer nível, dão lugar às ações que afetam o meio ambiente.

Similarmente, a Oliveira (2000), Dias (2004 p. 523) afirma que:

EA é um processo permanente no qual os indivíduos e a comunidade tomam consciência do seu meio ambiente e adquirem conhecimentos, valores, habilidades, experiências e determinação que os tornem aptos a agir e resolver problemas ambientais, presentes e futuros.

Dessa maneira, pode ser ressaltado, que a educação ambiental na escola ao ter como uma de suas finalidades o conhecimento da temática ambiental e, aliada à finalidade da escola de formar o indivíduo para a cidadania, cria assim, melhores perspectivas para mudanças necessárias em termos de comportamento e, dessa maneira, também sociais e ambientais.

Ressalta-se que a motivação do estudo em tela é a preocupação com o meio ambiente e a capacitação de profissionais da educação infantil afim de que, estando preparados, possam transmitir o seu conhecimento para as crianças na busca da formação de cidadãos mais responsáveis em relação ao meio ambiente. 
Embora, segundo Ramos (1999), Oliveira (2000), Dias (2004) e Oliveira (2012), a temática ambiental seja tema recorrente na mídia, assim como nos debates acadêmicos e, já exista uma política oficial por parte do Estado e de instituições internacionais como a ONU para a junção da educação com as questões ambientais e, assim, a promoção da educação ambiental na educação básica, destaca-se ainda a necessidade de se manter e ampliar a discussão sobre a problemática ambiental no universo escolar e, no caso em específico, no ensino infantil, promovendo sua relevância social visto o crescimento da preocupação das sociedades atuais com essa temática e as consequências das ações humanas junto à natureza.

Em assim sendo, a presente pesquisa procurou também, identificar, analisar e destacar metodologias que possam se promotoras da educação ambiental na educação infantil, auxiliando assim, com o processo de conscientização do indivíduo humano em sua inter-relação com o meio ambiente.

\section{METODOLOGIA}

Esta pesquisa teve caráter qualitativo e foi desenvolvida por meio de revisões bibliográficas, tendo sido realizadas leituras em livros, artigos, monografias, dissertações, teses, entre outros.

Lakatos e Marconi (2006) explicam que a pesquisa bibliográfica é o levantamento de bibliografias já publicadas, portanto, realizar a leitura de diversos materiais é fundamental para exemplificar, comprovar ou discordar de conhecimentos prévios adquiridos por meio do senso comum e mantendo, assim, sempre em debates questões importantes à sociedade como um todo. Ainda, segundo os mesmos autores, (LAKATOS e MARCONI, 2006, p. 15), o uso da pesquisa visa "[...] encontrar respostas para questões propostas, utilizando métodos científicos", o que colabora para a credibilidade das análises envolvidas.

Efetivamente, Lakatos e Marconi $(2009$, p. 25) ressaltam que "a pesquisa bibliográfica é um apanhado geral sobre os principais trabalhos já realizados, revestidos de importância por serem capazes de fornecer dados atuais e relevantes relacionados com o tema", sendo as novas análises efetuadas, por si só, contribuintes ao processo de reflexão do conhecimento das temáticas abordadas.

Os resultados estão sendo apresentados buscando os possíveis objetivos a serem alcançados em termos da inserção da educação ambiental em ambientes escolares promotores do ensino infantil e os mesmos serão divulgados à sociedade por meio de publicações científicas, participação em Seminários, Encontros, Jornada de Educação, Congressos Científicos e por dispositivos informatizados.

\section{RESULTADOS}

O meio ambiente faz parte do dia a dia das pessoas, é um tema amplo e de grande importância, porém, talvez por falta de conhecimento e/ou dificuldades de acesso a informações, ainda não é bem trabalhado e desenvolvido corretamente, principalmente no lugar de maior socialização, ou seja, nas escolas. Estando, segundo Ramos (1999), ligados à grandes temas nacionais, por exemplo, como o desmatamento da Amazônia e distante das realidades locais dos municípios e, mesmo dos ambientes escolares e o ambiente proporcionado pelo próprio corpo do indivíduo.

Segundo Sánchez (2008, p.18), o conceito de "ambiente", no campo do planejamento e gestão ambiental, é amplo, multifacetado e maleável. Amplo porque pode incluir tanto a natureza como a sociedade. Multifacetado porque pode ser apreendido sob diferentes perspectivas. Maleável porque, ao ser amplo e multifacetado, pode ser reduzido ou ampliado de acordo com as necessidades do analista ou os interesses dos envolvidos. 
Nesses termos, percebe-se que a falta de capacitação adequada do educador implica na abordagem incorreta sobre o tema, distanciando-se da realidade em que vive e na qual vive o seu aluno.

Para mediar o processo de ensino e aprendizagem é preciso ter conhecimento sobre os temas envolvidos e sobre a sua própria realidade e a de seus alunos. Indo mais além, é necessário acreditar e colocar em prática, antes de passar isso para a criança. Para tanto, segundo Ramos (1999), é necessário, além da abordagem da temática, a sua ampliação mediante uma educação direcionada e planejada com vistas ao exercício de comportamentos condizentes com a sustentabilidade ambiental.

Diante da preocupação que existe sobre os cuidados com o meio ambiente este trabalho ressalta que, um educador bem preparado, desenvolve com mais clareza o processo de ensinoaprendizagem, proporcionando aos alunos da educação infantil possibilidades de pensamento crítico e consciente.

Oliveira (2012, p. 50) ressalta esse aspecto dizendo que: "[...], a sustentabilidade e o não desperdício dos recursos naturais são constituídos como valor para as crianças por meio de hábitos que se aprendem desde cedo". Em decorrência disso é que o mesmo autor (OLIVEIRA, 2012, p. 51), considera que "[...] de pouco adianta desenvolver projetos sobre o meio ambiente se a escola não se organiza de modo sustentável e responsável no consumo dos bens naturais". Nesse aspecto, portando, a escola e os profissionais nela inseridos, devem se pautar pela construção de ambientes que sejam significativos pelos exemplos das práticas que realiza e não apenas pelos discursos teóricos.

Destacando a importância dos valores sobre o meio ambiente, é nesta fase escolar - ensino infantil - que são construídos a base que a criança vai levar para o futuro. Segundo Oliveira (2012, p. 51), "[...] crianças prestam muita atenção a tudo o que veem mesmo quando não intencionamos, procuram coerência entre o que falamos e o que realmente fazemos". Contudo revisando as palavras de Oliveira (2012), a criança quando já conscientizada, observa sua rotina diária e tenta fazer alterações em seu comportamento e, por conseguinte, à todos em sua volta.

Para Oliveira (2012), os educadores são importantes nesse processo:

Os professores são fonte inesgotável de modelos e, por isso mesmo, é tão importante explicitar às crianças a intenção que está por trás de cada atitude. Daí que para constituir hábitos de cuidado, de preservação e não desperdício dos recursos naturais, as crianças precisam encontrar no ambiente e nas atitudes dos professores [...]. (P. 51)

O educador e a escola devem, portanto, levar sempre em consideração, que a criança está em processo de desenvolvimento e é mais flexível à mudanças, tornando, assim, mais viável e/ou facilitado o trabalho com o objetivo de formar cidadãos e cidadãs responsáveis e praticantes junto à sociedade e com os cuidados em relação ao meio ambiente necessários em termos de sustentabilidade ambiental, entendendo esta, conforme Ramos (1999) e Oliveira (2000), como o equilíbrio entre as necessidades humanas e as necessidades da própria natureza em si.

Frente às possíveis dificuldades encontradas pelo professor, faz-se necessário a construção de metodologias a serem utilizadas em sala de aula e no ambiente escolar como um todo, que proporcionem mudanças no fazer pedagógico do educador e da escola e, estas, só podem ocorrer através de atividades diferenciadas, concretas e próximas às múltiplas realidades vivenciadas pelo educador e pelos alunos. Para tanto, o professor e a escola, devem estar sempre atentos ao que está ocorrendo no ambiente em que está com seus alunos e considerar que nessa fase da educação - ensino infantil - que a criança aprende trabalhando com elementos concretos, sendo 
importante colocar os assuntos em debates coletivos, durante os momentos, por exemplo, de rodas de conversas, do planejamento etc.

\section{DISCUSSÃO}

O processo de socialização e, portanto, de formação do indivíduo, tem início na família e perpassa por diferentes ambientes sociais valorizados pela sociedade, dentre eles, a escola. Segundo Chauí (2004) e Demo (2004), o processo de socialização do indivíduo implica no recebimento de toda carga cultural que forma e permeia a sociedade, o que não significa dizer que essa cultura é, por si só, perfeita, muito pelo contrário, necessita de constantes revisões e aprimoramentos. Nesses termos, da necessidade não só da formação do indivíduo, mas de revisitar reflexivamente a própria cultura e, consequentemente, o modo de ser e de se conviver em sociedade, é que se faz necessário uma educação mais objetiva em termos de melhoramento das relações humanas entre si e com o meio ambiente.

Levando-se em consideração que a criança está em processo de desenvolvimento e é mais flexível à mudanças, torna-se viável o desenvolvimento de práticas reflexivas, contemplativas ou mesmo exemplificativas com o objetivo de formar cidadãos responsáveis e praticantes junto à sociedade com os devidos cuidados em relação ao meio ambiente é que se destaca a importância da educação ambiental (EA).

É consenso entre os pesquisadores citados, como Ramos (1999), Oliveira (2000), Dias (2004), Oliveira (2012) entre outros, que a EA deve ser trabalhada visando a relação do ser humano com a natureza. Reigota (2009, p. 14) apresenta ainda que "a educação ambiental deve procurar favorecer e estimular possibilidades de se estabelecer coletivamente uma 'nova aliança'", possibilitando, assim, à todas as espécies, a possiblidade de convivência e sobrevivência com dignidade.

Conforme Reigota (2009 p. 14), a Educação Ambiental possui vieses com a Educação Política, pois "possibilita ao cidadão aprender e conhecer os seus direitos podendo exigir uma sociedade com mais justiça social e ética com o meio" e, participar dela de maneira mais justa e ambientalmente sustentável.

Baptista (2012 p. 6) destaca ainda, a Educação Ambiental como um "processo de educação política, cujo objetivo é formar atitudes que predisponham à ação". Para tanto é necessária a formação de cidadãos críticos e reflexivos, atuantes em uma sociedade que busque e se paute pela igualdade, a solidariedade e o respeito. Similarmente, Reigota (2009 p. 14) descreve que a educação ambiental "[...] como educação política enfatiza antes a questão 'por que fazer do que 'como' fazer". Dessa maneira, em tendo a educação ambiental esse viés político, encaminha-se no sentido de uma pedagogia que promova maior interação entre o homem e a natureza e que, consequentemente, também seja uma educação que eleve a verdadeira cidadania, qual seja, aquela que deve envolver, necessariamente, amplas possibilidades de participação do indivíduo.

\section{CONCLUSÃO}

Considerando a análise efetuada com a revisão bibliográfica, percebe-se que, apesar das discussões sobre as relações entre sociedade e natureza já terem, segundo Ramos (1999) e outros autores citados, muitas décadas, provavelmente séculos, a mesma ainda se faz necessária. Essa necessidade decorre pelo simples fato de que as sociedades, de maneira geral, ainda estabelecem a consolidação de modos de vida que só têm provocado contínua degradação dos ambientes naturais e também culturais. Destacando como culturais, tanto os ambientes urbanos e rurais, pois ambos sofrem processos de degradação, mas também, o próprio ser humano, física e biologicamente. $\mathrm{O}$ corpo humano em si, é um ambiente que também se degrada, haja visto o crescente número de pessoas com problemas relacionados ao excesso de consumo, quer seja esse de bens estéticos e mesmo de alimentação, dos quais decorrem, por exemplo, à obesidade e os 
problemas de saúde a ela relacionados. O consumismo exagerado é um dos aspectos que a educação ambiental deve abordar e buscar a conscientização do ser humano que se consome no próprio processo.

Diante disso, ou seja, de um cenário de contínua degradação ambiental e também corporal e social, é que se faz necessário processos educativos, de forma sistematizada e permanente, com vistas à formação das parcelas mais jovens da sociedade no sentido de comportamentos mais condizentes com a sustentabilidade ambiental. Para tanto, é importante o desenvolvimento desse processo já nas fases iniciais da formação do indivíduo, quer seja no seio familiar ou escolar.

Em termos do ambiente escolar, busca-se a educação ambiental que promova a conscientização do ser humano para práticas sustentáveis, sendo que esta deve ser iniciada ainda no ensino infantil, possibilitando à criança, nessa fase escolar, possibilidades de sensibilização e/ou reflexão sobre suas ações e possíveis consequências ao meio ambiente.

Para que a educação ambiental escolar no ensino infantil passe de mera possibilidade para uma realidade concreta, são necessários a preparação adequada do educador e a consolidação no ambiente escolar de políticas educacionais e práticas educativas voltadas à temática ambiental e a consolidação de um ambiente democrático e, consequentemente, aberto à participação coletiva de pais, alunos e equipe escolar.

\section{REFERÊNCIAS}

BAPTISTA, Vinícius Ferreira. A educação ambiental para um ambiente equilibrado. Saúde \& Amb. Rev., Duque de Caxias, v.7, n.1, p.01-09, jan-jun 2012. Disponível em: http://publicacoes.unigranrio.br/index.php/sare/article/viewFile/1658/828 acesso em 14/05/2016

CHAUÍ, Marilena. Convite à Filosofia. São Paulo : Ática, 2004.

DEMO, Pedro. Sociologia da Educação - Sociedade e suas oportunidades. Brasília : Plano Editora, 2004.

DIAS, Genebaldo Freire. Educação ambiental princípios e práticas. São Paulo: Gaia, 2004, 9 ed. LAKATOS, Eva Maria. MARCONI, Marina de Andrade. Técnicas de Pesquisa. São Paulo: Atlas S.A. 2006, 6 ed.

Metodologia do trabalho científico. São Paulo: Atlas S.A. 2009, 7 ed.

OLIVEIRA, Elísio Márcio de. Educação ambiental uma possível abordagem. Brasília: Ibama, 2000, 2 ed.

OLIVEIRA, Zilma Ramos de (org). O Trabalho do professor na educação infantil. São Paulo: Biruta, 2012, 1 ed.

RAMOS, Marcos Lupércio. A temática ambiental e a Formação de Professores no Curso de Habilitação Específica para o Magistério em Regente Feijó-SP. Dissertação de Mestrado apresentada à Faculdade de Ciências e Filosofia da Univerdade Estadual "Júlio de Mesquita Filho". Marília : UNESP, 1999.

REIGOTA, Marcos. O que é educação ambiental. São Paulo : Brasiliense, 2009.

SÁNCHEZ, Luis Enrique. Avaliação de impacto ambiental conceitos e métodos. São Paulo: Oficina de Textos, 2008. 